\title{
Risk factors for acquisition of gentamicin-resistant enterococcal infection: a case-controlled study
}

\author{
M Viagappan, R E Holliman
}

\begin{abstract}
Summary
High-level gentamicin-resistant enterococci present problems in the treatment of infected patients, especially as synergy between penicillin and gentamicin is lost. Previous studies have suggested various risk factors for the acquisition of these enterococci. A case-controlled study was performed on 17 patients infected with resistant enterococci and 26 infected with sensitive strains who attended a London hospital. The key risk factors for acquisition of infection with high-level gentamicin-resistant enterococci were found to be prior prolonged antibiotic treatment, use of five or more antibiotics, and the presence of a urinary catheter. It is proposed that infection control measures should be targeted at patients at higher risk. In addition, control of antibiotic usage in a hospital may help to prevent acquisition and spread of these organisms.
\end{abstract}

Keywords: gentamicin-resistant enterococci; enterococcal infection

Infection with high-level gentamicin-resistant (HLGR) enterococci is an increasing clinical problem. ${ }^{12}$ Studies from North America suggest nosocomial spread as the major route of acquisition. ${ }^{13-5}$ A number of features, including length of hospital stay and antibiotic usage, have been identified as risk factors for acquisition of these organisms.

Studies of the epidemiology of HLGR enterococcal infection have not been performed in the UK. A study was undertaken to see if colonisation factors identified in the USA were consistent with infection-related factors in a UK hospital and whether further risk factors could be detected. With the identification of important risk factors, appropriate control measures might be introduced to control the spread of infection with these organisms or prevent their emergence from the outset.

\section{Methods}

Department of Medical Microbiology, St George's Hospital \& Medical School, Blackshaw Road, London SW17 0QT, UK $M$ Viagappan

R E Holliman

Accepted 14 January 1999
The study was based on retrospective review of hospital patients' notes.

STUDY SUBJECTS

The case definition was a patient from whom a blood culture isolate of HLGR enterococcus had been grown and who had documented evidence of a clinical infection attributable to this organism. Patients were identified using the blood culture records kept in the microbiology department of the hospital and from hospital case notes. For each patient with HLGR enterococci isolated from blood cultures and who fitted the case definition, the previous and (where possible) next patient listed in the blood culture isolate book with a gentamicin-sensitive enterococcus were chosen as controls.

BACTERIAL STRAINS

All enterococci isolated from blood cultures were reviewed over a 2-year period. These isolates were retrieved from nutrient agar slopes (Oxoid CM 3) and plated out onto 5\% horse blood agar to check for viability and purity prior to antibiotic testing. Definitive identification of organisms used the API 20 STREP system.

TESTING FOR AMINOGLYCOSIDE RESISTANCE

HLGR strains were defined as those with a minimum inhibitory concentration (MIC) of $>1000 \mu \mathrm{g} / \mathrm{ml}$. MIC testing was undertaken

Table 1 Comparison of clinical features in patients infected with enterococci highly resistant or sensitive to gentamicin

\begin{tabular}{|c|c|c|c|}
\hline Factor & $\begin{array}{l}\text { Resistant } \\
\text { patients } \\
(n=17)\end{array}$ & $\begin{array}{l}\text { Sensitive } \\
\text { patients } \\
(n=26)\end{array}$ & $p$-Value \\
\hline \multicolumn{4}{|l|}{ Sex } \\
\hline Male & 8 & 14 & 0.67 \\
\hline Female & 9 & 12 & 0.67 \\
\hline \multicolumn{4}{|l|}{ Age (years) } \\
\hline $0-1$ & 0 & 9 & 0.006 \\
\hline $1-60$ & 6 & 4 & 0.13 \\
\hline $60+$ & 11 & 13 & 0.85 \\
\hline \multicolumn{4}{|l|}{ Days on ward } \\
\hline $1-14$ & 7 & 16 & 0.19 \\
\hline$>14$ & 10 & 10 & 0.19 \\
\hline \multicolumn{4}{|l|}{ Unit } \\
\hline Medical & 8 & 9 & 0.41 \\
\hline Surgical & 9 & 9 & 0.23 \\
\hline ITU & 5 & 6 & 0.64 \\
\hline SCBU & 0 & 8 & 0.011 \\
\hline \multicolumn{4}{|l|}{ Catheter } \\
\hline Urinary & 10 & 6 & 0.017 \\
\hline Indwelling/IV & 10 & 10 & 0.19 \\
\hline \multicolumn{4}{|c|}{ Prior antibiotic therapy } \\
\hline Yes & 15 & 15 & 0.032 \\
\hline No & 1 & 11 & 0.009 \\
\hline Not known & 1 & & \\
\hline \multicolumn{4}{|c|}{ Number of antibiotics } \\
\hline $1-4$ & 11 & 14 & 0.48 \\
\hline $5+$ & 4 & 1 & 0.04 \\
\hline \multicolumn{4}{|c|}{ Period of therapy (days) } \\
\hline $1-14$ & 10 & 14 & 0.74 \\
\hline$>14$ & 4 & 1 & 0.04 \\
\hline \multicolumn{4}{|l|}{ Type of therapy } \\
\hline Gentamicin & 4 & 6 & 0.97 \\
\hline Penicillin & 5 & 8 & 0.92 \\
\hline Cephalosporin & 13 & 12 & 0.05 \\
\hline
\end{tabular}


Table 2 Clinical details and source of sepsis

\begin{tabular}{|c|c|c|}
\hline Case & Clinical details & Source of sepsis \\
\hline \multicolumn{3}{|c|}{ Year 1 Gentamicin sensitive } \\
\hline 1 & Premature infant $27 / 40$ with intra-uterine growth retardation; patent ductus arteriosis ligated & Not established \\
\hline 2 & Ruptured aortic aneurism; pulsatile tender mass in abdomen; aneurism repaired. & Abdominal \\
\hline 3 & Pale, pulseless left foot. Left angioplasty. Postoperative bleeding. Retroperitoneal haematoma. & Abdominal \\
\hline 4 & $\begin{array}{l}\text { Known carcinoma of breast and abdominal metastases. Previously, biliary stent for obstruction due to liver } \\
\text { metastases. }\end{array}$ & Abdominal \\
\hline 5 & Four day old term baby. Jaundice at day 3. Septic screen taken. & Not established \\
\hline 6 & Liver abscess drained and cholecystectomy & Hepatobiliary or abdominal \\
\hline 7 & Laparotomy for bowel obstruction. Right hemicolectomy performed. & Abdominal \\
\hline 8 & ERCP; Gallstones in common bile duct; sphincterotomy performed. & Biliary tract \\
\hline 9 & Preterm infant $25 / 40$; prolonged oxygen dependency & Not established \\
\hline 10 & Diabetic patient, ischaemic vascular disease of right foot. & Right foot \\
\hline 11 & 3/7 ultrasound - gallstone seen; $4 / 7$ cholecystectomy performed. & Biliary tract \\
\hline 12 & $\begin{array}{l}1 \text { month old child with decreased appetite and fever. Raised white cell count. Developed diarrhoea. Settled on } \\
\text { ward. }\end{array}$ & Not established \\
\hline 13 & Chicken-pox pneumonia; prolonged stay on ITU & Line sepsis \\
\hline 14 & Post-op oesophagogastrectomy. Pleural drain fluid grew faecal streptococci. & Pleural cavity or abdominal \\
\hline 15 & Post-op repair of cerebral AV malformation. Developed bowel perforation. Laparotomy; duodenal ulcer oversewn. & Abdominal \\
\hline \multicolumn{3}{|c|}{ Year 1 Gentamicin resistant } \\
\hline 16 & Cholangio-carcinoma; biliary stent inserted; febrile post operation & Biliary tract \\
\hline 17 & $\begin{array}{l}\text { Admitted with injury to left femur and foot and amputated thumb following accident. Left below knee } \\
\text { amputation;septic post-op. Skin graft pus from left hand grew faecal streptococci }\end{array}$ & Wounds \\
\hline 18 & Carcinoma of oesophagus; oesophago-gastrectomy. & Chest and abdominal \\
\hline 19 & Rheumatic heart disease. Cardiac catheterisation. Small haematoma around catheterisation site. & UTI or groin wound \\
\hline 20 & Burns; ITU care needed & UTI \\
\hline 21 & Diabetic patient; long term indwelling urinary catheter. Acute abdomen. Gangrenous bowel resected. & Abdominal \\
\hline 22 & High grade non-Hodgkins lymphoma. Developed cellulitis below knees and leukaemic meningitis. & Probably abdominal \\
\hline 23 & $\begin{array}{l}\text { Bradycardia. Pacing wire inserted. Cardiac arrest. Resuscitated. CABG performed; pacemaker reinserted. Febrile. } \\
\text { Sternal wound swab grew faecal streptococci. Wound swab from second Swan Gantz; insertion site grew group D } \\
\text { strep. }\end{array}$ & Sternal wound; line sepsis. \\
\hline 24 & $\begin{array}{l}\text { History of presumptive pure motor-neuropathy. Admitted with increasing breathing difficulties; plasmapheresis. } \\
\text { Patient developed rigors post-line insertion. }\end{array}$ & Line sepsis \\
\hline 25 & Emphysema. Psoriasis treated with methotrexate; developed pancytopenia and scrotal sores. & Scrotal sores \\
\hline 26 & Abdominal pain and vomiting. Previous rectal carcinoma. Small bowel resected. Gangrenous bowel present. & Abdominal \\
\hline 27 & Chronic renal failure. Hydronephrotic kidneys. & Urinary tract \\
\hline \multicolumn{3}{|c|}{ Year 2 Gentamicin sensitive } \\
\hline 28 & $34 / 40$ child with cardiac conduction defect and tachycardia. On TPN feeding. & Not established \\
\hline 29 & Jaundice, gallstones & Biliary tract \\
\hline 30 & Bladder carcinoma, acute retention, prostatic hypertrophy. Faecal streptococci isolated from catheter urine & Urinary tract \\
\hline 31 & Right lobe pneumonia, atrial fibrillation. Sputa grew haemophilus influenza. & Chest \\
\hline 32 & $26 / 40$ infant; bilateral intra-ventricular haemorrhages; hydrocephalus needing tapping of CSF. TPN feeding. & Line sepsis \\
\hline 33 & $28 / 40$ triplet. Collapsed day $14 ;$ on TPN feeding. & Line sepsis \\
\hline 34 & $28 / 40$ triplet. Poor respiratory effort; on TPN feeding. & Possible line sepsis \\
\hline 35 & Angina. Cardiac catheterisation, repeat catheterisation & Sternal wound; line sepsis \\
\hline 36 & 29/40 baby, cyanosis at birth. Ventilated. distended abdomen. Blood-stained gastric aspirate. & Abdomen \\
\hline 37 & Abdominal pain, obstructive jaundice; laparotomy for biliary peritonitis & Biliary tract \\
\hline 38 & Abdominal pain, gallstones & Biliary tract \\
\hline \multicolumn{3}{|c|}{ Year 2 Gentamicin resistant } \\
\hline \multirow[t]{2}{*}{39} & i) carcinoma of breast & Possibly: i) abdominal \\
\hline & ii) liver metastases; biliary stent inserted for obstruction & ii) biliary tract \\
\hline 40 & Aplastic anaemia. Bone marrow transplant. & Not established \\
\hline \multirow{3}{*}{41} & i) acute pancreatitis & i) abdomen \\
\hline & ii) diabetes & ii) line sepsis \\
\hline & Acute renal failure, duodenal ulcer and gastrointestinal bleed. TPN line grew group D streptococcus. & \\
\hline 42 & Abdominal hysterectomy, bowel perforated post-op, laparotomy and resection. & Abdomen \\
\hline \multirow[t]{3}{*}{43} & i) road traffic accident & i) chest \\
\hline & ii) head and chest injuries; & ii) line sepsis \\
\hline & Multiple limb fractures; fractures pinned. Chest drain site swab grew faecal streptococci. & \\
\hline
\end{tabular}

using the multi-point inoculation method. Mueller-Hinton agar plates (Oxoid CM337) were prepared and gentamicin incorporated at concentrations of $0.5,1,2,4,8,16$, and 1000 $\mu \mathrm{g} / \mathrm{ml}$. Plates were also prepared without antibiotic to check for satisfactory bacterial growth. Each isolate was inoculated into brain heart infusion broth (Oxoid CM225) incubated at $37^{\circ} \mathrm{C}$ overnight to produce an organism concentration of approximately $10^{7}$ $\mathrm{cfu} / \mathrm{ml}$. An inoculum of this suspension was delivered to the plates by a manual inoculator delivering $1 \mu \mathrm{l}\left(10^{4} \mathrm{cfu}\right)$ per spot. The plates were then incubated at $37^{\circ} \mathrm{C}$ in air for 24 hours and examined using a magnifying glass to establish the lowest concentration of antibiotic which inhibited growth.
ANALYSIS OF CLINICAL DATA

The notes of all patients with enterococcal infection were reviewed. Patient details were collected according to the protocol of Axelrod et al. ${ }^{4}$ Information collected on a standard form included location of the patient, microbiological results, clinical details prior to the isolation of enterococci, and type and duration of antibiotic therapy during the current admission and from any referring hospital. The presence of a urinary or vascular catheter at any time during the admission was noted.

\section{STATISTICAL ANALYSIS}

Analysis of findings was performed by comparing clinical and demographic features in patients with sensitive enterococcal infection 
and those infected with HLGR enterococci. Significance levels were calculated using the EPI Info 5 software package for Epidemiology and Disease surveillance.

\section{Results}

A total of 17 patients infected with HLGR enterococci and 26 patients infected with susceptible strains were identified. A comparison of clinical features between the two groups is presented in table 1 .

There was no association between infection with HLGR enterococci and sex or length of hospital stay. No increase in HLGR enterococcal infection was found in patients over 60 years old, but a significant number of patients with a sensitive strain were young babies. No one age group appeared to be linked to an increased risk of acquiring resistant enterococci. There was a strong association found between sensitive enterococcal infection and admission to the special care baby unit, but no HLGR enterococcus was isolated from a child on the special care baby unit.

An association was detected between HLGR enterococcal infection and the presence of a urinary catheter but not with the presence of intravascular catheters. There was a marked association between HLGR enterococcal infection and previous antibiotic therapy. Most patients with HLGR infection had previous antibiotic treatment. In patients who had not received antibiotics the infection was usually due to sensitive enterococcus. Use of five or more antibiotics and treatment for 14 days or more were both associated with HLGR enterococcal infection. HLGR enterococcal infection was more frequently found with prior cephalosporin therapy but not with penicillin or gentamicin. The cephalosporins used, with one exception, were second or third generation.

Table 3 Antibiotic susceptibility findings

\begin{tabular}{|c|c|c|c|c|c|c|c|c|}
\hline \multicolumn{2}{|l|}{ Patient } & $A m p$ & Ctx & $C h l$ & Ery & Gent100 & Trim & Other \\
\hline \multicolumn{9}{|c|}{ Year 1 Gentamicin sensitive } \\
\hline 1 & E faecalis & $S$ & $\mathrm{~S}$ & $\mathrm{R}$ & $\mathrm{S}$ & $\mathrm{S}$ & $S$ & \\
\hline 2 & E faecalis & $S$ & $\mathrm{~S}$ & $S$ & $\mathrm{~S}$ & $\mathrm{~S}$ & - & Imi sens \\
\hline 3 & $\mathrm{f} / \mathrm{s}$ & $\mathrm{S}$ & $\mathrm{R}$ & $\mathrm{S}$ & $\mathrm{S}$ & $\mathrm{S}$ & - & \\
\hline 4 & $\mathrm{f} / \mathrm{s}$ & $\mathrm{S}$ & $\mathrm{R}$ & $\mathrm{R}$ & $\mathrm{S}$ & $\mathrm{S}$ & - & \\
\hline 5 & E faecalis & $\mathrm{R}$ & $\mathrm{S}$ & $\mathrm{S}$ & $\mathrm{S}$ & $\mathrm{S}$ & - & \\
\hline 6 & E faecalis & $\mathrm{S}$ & $S$ & $\mathrm{R}$ & $\mathrm{S}$ & $S$ & S & \\
\hline 7 & E faecalis & $\mathrm{R}$ & $\mathrm{R}$ & $\mathrm{R}$ & $\mathrm{R}$ & $\mathrm{S}$ & $\mathrm{S}$ & \\
\hline \multirow[t]{2}{*}{8} & Group D strep & $\mathrm{R}$ & $\mathrm{R}$ & $\mathrm{S}$ & $\mathrm{S}$ & - & $S$ & \\
\hline & Group D strep & $S$ & $\mathrm{R}$ & $S$ & $\mathrm{~S}$ & $\mathrm{~S}$ & - & \\
\hline 9 & $\mathrm{f} / \mathrm{s}$ & $\mathrm{S}$ & $\mathrm{R}$ & $\mathrm{S}$ & $\mathrm{S}$ & $\mathrm{S}$ & - & \\
\hline 10 & $\mathrm{f} / \mathrm{s}$ & $\mathrm{S}$ & $\mathrm{s}$ & $\mathrm{R}$ & $\mathrm{R}$ & $\mathrm{s}$ & $\mathrm{R}$ & \\
\hline 11 & Group D strep & $S$ & $S$ & $\mathrm{R}$ & $\mathrm{R}$ & $\mathrm{S}$ & - & \\
\hline 12 & $\mathrm{f} / \mathrm{s}$ & $\mathrm{S}$ & $\mathrm{S}$ & $\mathrm{R}$ & $\mathrm{R}$ & $\mathrm{S}$ & $\mathrm{R}$ & \\
\hline 13 & Strep faecalis & $\mathrm{S}$ & $\mathrm{S}$ & $\mathrm{S}$ & $\mathrm{S}$ & $\mathrm{S}$ & $\mathrm{R}$ & \\
\hline 14 & E faecalis & $\mathrm{S}$ & $\mathrm{R}$ & - & $\mathrm{S}$ & $\mathrm{S}$ & - & \\
\hline 15 & E faecium & $\mathrm{R}$ & $S$ & $\mathrm{R}$ & $\mathrm{R}$ & $S$ & $\mathrm{R}$ & \\
\hline \multicolumn{9}{|c|}{ Year 1 Gentamicin resistant } \\
\hline 16 (2 sets) & E faecalis & $\mathrm{S}$ & $\mathrm{R}$ & - & $\mathrm{R}$ & $\mathrm{R}$ & $\mathrm{R}$ & \\
\hline 17 & $\mathrm{f} / \mathrm{s}$ & $\mathrm{S}$ & $\mathrm{R}$ & $\mathrm{R}$ & $\mathrm{R}$ & $\mathrm{R}$ & $\mathrm{R}$ & Imi sens \\
\hline 18 & $\mathrm{f} / \mathrm{s}$ & $\mathrm{s}$ & $\mathrm{R}$ & $\mathrm{R}$ & $\mathrm{R}$ & $\mathrm{R}$ & $\mathrm{R}$ & \\
\hline 19 & Group D strep & $S$ & $\mathrm{~S}$ & $\mathrm{R}$ & $\mathrm{R}$ & $\mathrm{R}$ & - & \\
\hline 20 & E faecalis & $\mathrm{S}$ & $\mathrm{R}$ & $\mathrm{s}$ & $\mathrm{R}$ & $\mathrm{R}$ & $\mathrm{R}$ & \\
\hline 21 & E faecalis & $\mathrm{s}$ & $\mathrm{R}$ & $\mathrm{R}$ & $\mathrm{R}$ & $\mathrm{R}$ & $\mathrm{R}$ & \\
\hline 22 & $\mathrm{f} / \mathrm{s}$ & $\mathrm{S}$ & $\mathrm{R}$ & $\mathrm{R}$ & $\mathrm{R}$ & $\mathrm{R}$ & $\mathrm{R}$ & \\
\hline 23 & $\mathrm{f} / \mathrm{s}$ & $\mathrm{S}$ & $\mathrm{R}$ & $\mathrm{R}$ & $\mathrm{R}$ & $\mathrm{R}$ & $\mathrm{R}$ & \\
\hline 24 & E faecalis & $\mathrm{R}$ & $\mathrm{R}$ & $\mathrm{R}$ & $\mathrm{R}$ & $\mathrm{R}$ & $\mathrm{R}$ & \\
\hline 25 & $\mathrm{f} / \mathrm{s}$ & $\mathrm{S}$ & $\mathrm{R}$ & $\mathrm{R}$ & $\mathrm{R}$ & $\mathrm{R}$ & $\mathrm{R}$ & \\
\hline \multirow[t]{2}{*}{26} & $\mathrm{f} / \mathrm{s} 1$ & $\mathrm{~S}$ & $\mathrm{~S}$ & - & $\mathrm{R}$ & $\mathrm{R}$ & - & \\
\hline & $\mathrm{f} / \mathrm{s} 2$ & $\mathrm{R}$ & $\mathrm{R}$ & - & $\mathrm{S}$ & $\mathrm{S}$ & - & \\
\hline 27 & E faecalis & S & $\mathrm{R}$ & $S$ & $S$ & $\mathrm{R}$ & - & \\
\hline \multicolumn{9}{|c|}{ Year 2 Gentamicin sensitive } \\
\hline 28 & E faecalis & $S$ & S & $S$ & $\mathrm{~S}$ & $\mathrm{~S}$ & S & \\
\hline 29 & E faecalis & $\mathrm{s}$ & - & $\mathrm{R}$ & $\mathrm{s}$ & $\mathrm{s}$ & - & Tet res \\
\hline 30 & E faecalis & $S$ & - & $\mathrm{S}$ & $\mathrm{S}$ & $\mathrm{S}$ & - & Tet sens \\
\hline 31 & Enterococcus $\mathrm{sp}$ & $\mathrm{R}$ & - & $\mathrm{S}$ & $\mathrm{S}$ & $\mathrm{S}$ & - & Tet sens \\
\hline 32 & E faecalis & $\mathrm{S}$ & $\mathrm{R}$ & $\mathrm{R}$ & $S$ & $\mathrm{~S}$ & - & Van sens \\
\hline 33 & Group D strep & $\mathrm{S}$ & - & $\mathrm{R}$ & $\mathrm{R}$ & $\mathrm{S}$ & - & Tet res \\
\hline 34 & Group D strep & S & - & $\mathrm{S}$ & $\mathrm{S}$ & $\mathrm{S}$ & - & Tet sens \\
\hline \multirow[t]{3}{*}{35 (2 sets) } & $\mathrm{f} / \mathrm{s} 1$ & $\mathrm{~s}$ & - & $\mathrm{R}$ & $\mathrm{s}$ & $\mathrm{s}$ & - & Tet res \\
\hline & $\mathrm{f} / \mathrm{s} 2$ & S & - & $\mathrm{R}$ & $\mathrm{S}$ & $\mathrm{S}$ & - & Tet res \\
\hline & $\mathrm{f} / \mathrm{s} 3$ & $\mathrm{~S}$ & - & $\mathrm{S}$ & $\mathrm{S}$ & $\mathrm{S}$ & - & Tet res \\
\hline 36 & E faecalis & $\mathrm{R}$ & - & $\mathrm{R}$ & $\mathrm{S}$ & $\mathrm{S}$ & $\mathrm{R}$ & Vanc sens \\
\hline 37 & E faecium & $\mathrm{R}$ & - & $\mathrm{R}$ & $\mathrm{R}$ & $S$ & - & \\
\hline 38 & E faecium & $\mathrm{R}$ & - & $\mathrm{R}$ & $\mathrm{R}$ & $\mathrm{S}$ & - & \\
\hline \multicolumn{9}{|c|}{ Year 2 Gentamicin resistant } \\
\hline 39 & E faecium & $\mathrm{R}$ & $\mathrm{R}$ & $\mathrm{S}$ & $\mathrm{R}$ & $\mathrm{R}$ & - & Vanc sens \\
\hline 40 & E faecalis & $\mathrm{s}$ & - & $\mathrm{R}$ & $\mathrm{R}$ & $\mathrm{R}$ & - & Tet res \\
\hline 41 (2 sets) & E faecalis & $\mathrm{S}$ & $\mathrm{R}$ & $\mathrm{R}$ & $\mathrm{R}$ & $\mathrm{R}$ & - & \\
\hline 42 & Group D strep & $\mathrm{S}$ & - & $\mathrm{R}$ & $\mathrm{R}$ & $\mathrm{R}$ & - & Vanc, Teic sens; Tet res \\
\hline 43 & E faecalis & $S$ & $\mathrm{R}$ & $\mathrm{R}$ & $\mathrm{R}$ & $\mathrm{R}$ & - & Vanc, Rif sens; Septrin, Cip res \\
\hline
\end{tabular}

Key: $\mathrm{f} / \mathrm{s}=$ faecal streptococcus; $\mathrm{S}$, sens = sensitive; $\mathrm{R}$, res = resistant $\mathrm{Amp}=$ ampicillin $; \mathrm{Ctx}=$ cefotaxime; Chl = chloramphenicol; Cip = ciprofloxacin $;$ Ery $=$ erythromycin $;$ Gent $=$ gentamicin $;$ Imi $=$ imipenem $;$ Rif $=$ rifampicin $;$ Teic $=$ teicoplanin; Tet $=$ tetracycline; $\operatorname{Tri}=$ trimethoprim; Vanc $=$ vancomycin $;-=$ not tested 
Table 2 gives a summary of clinical details and the suspected source of sepsis. Bacteraemia was mostly associated with sepsis of the gastrointestinal or biliary tract, although line and urinary sources were noted in some cases.

Table 3 gives the full set of known antibiotic sensitivities. Of 28 gentamicin-sensitive isolates, seven were resistant to ampicillin (three $E$ faecalis, three $E$ faecium, one not speciated). Out of 17 gentamicin-resistant isolates, three were resistant to ampicillin (one each of $E$ faecalis, and $E$ faecium and one not speciated).

\section{Discussion}

HLGR enterococci can cause difficulties in selecting appropriate therapy when clinical infection is present. The most important example is the loss of synergy between the aminoglycoside and penicillin, ${ }^{6}$ which presents problems in treating endocarditis. As HLGR enterococci become more common, serious infections such as endocarditis and osteomyelitis caused by them cannot be treated satisfactorily. ${ }^{7-9}$ Consequently, there is a need to limit the spread of these organisms by appropriate control of infection procedures.

An important step in controlling the spread of this organism is to identify the risk factors for acquisition and target infection control measures to 'at risk' patients, or preferably avoid the risk factors for acquisition from the start. This study demonstrated that patients were more likely to be infected with HLGR enterococci if they had prior antibiotic therapy, if they had received treatment with more than four antibiotics, or if therapy had included a cephalosporin. They were also more likely to be infected if they had a urinary catheter. Patients less likely to be infected with a HLGR enterococci were those who had received no prior antibiotic therapy and babies on the specialcare baby unit.

Previous workers have shown an association between colonisation or infection with HLGR enterococci and hospital stay of 14 days or longer. ${ }^{5}$ Such an association was not shown in

1 Zorvos MJ, Kauffman CA, Therasse PM, Bergman AG, Mikesell TS, Schaberg DR. Nosocomial infection by gentamicin-resistant Streptococcus faecalis. Ann Intern Med 1987;106:687-91

2 Noskin GA, Till M, Patterson BK, Clarke JT, Warren JR. High-level gentamicin resistance in Enterococcus faecalis bacteraemia. F Infect Dis 1991;164:1212-5.

3 Zervos MJ, Dembinski S, Mikesell T, Schaberg DR. High-level gentamicin in S faecalis: risk factors and evidence for exogenous acquisition of infection. I Infect Dis $1986 ; 153$ : 1075-83.

4 Murray BE, Singh KV, Markowitz SM, et al. Evidence for clonal spread of a single strain of a beta-lactamase producing Enterococcus (Streptococcus) faecalis. F Infect Dis 1991;163: $780-5$.

5 Axelrod P, Talbot GH. Risk factors for the acquisition of gentamicin resistant enterococci. Arch Intern Med 1989;149: 1397-401.

\section{Learning points}

- HLGR enterococcal endocarditis or osteomyelitis may fail to respond to conventional combination antibiotic therapy

- HLGR enterococcal infection is associated with prolonged antibiotic therapy, use of five or more antibiotics and the presence of a urinary catheter

- infection control measures should seek to control risk factors for the acquisition of HLGR enterococcal infection

the present study. However, our study was limited to patients with suspected enterococcal infection only and excluded colonisation.

Control of hospital spread of HLGR enterococci might be achieved by screening for carriage and subsequent isolation of carriers. It is important to decide in advance which group of patients it would be most effective to screen, and it must be clear why screening is being done. The aims of screening and isolation would be to protect the individual patient from infection with resistant enterococci, particularly patients at risk of endocarditis and osteomyelitis where synergistic therapy with a betalactam and an aminoglycoside would be used. Additional aims would be to prevent crossinfection of other patients and prevent spread to neighbouring hospitals. Rather than swab all patients, some workers have suggested that it would be a more efficient use of hospital resources to target a high-risk population of patients such as those identified in this and other studies ${ }^{10}$ as being at enhanced risk for HLGR enterococcal infection.

An alternative strategy would be to limit potential risk factors in an attempt to prevent resistance emerging. Such a policy would include strict control of antibiotic usage on the ward and the avoidance of unnecessarily prolonged courses of antibiotics or unnecessary long-term urinary catheterisation. Prospective studies are required to evaluate the relative merits of these procedures.

6 Moellering RC. The enterococcus: a classic example of the impact of antimicrobial resistance on therapeutic options. $\mathcal{F}$ Antimicrob Chemother 1991;28:1-12.

7 Fernandez-Guerrero ML, Barros C, Rodriguez Tudela JL, Roblas RF, Soriano F. Aortic endocarditis caused by gentamicin-resistant Enterococcus faecalis. Eur 7 Clin Microgentamicin-resistant Enterococc
biol Infect Dis 1988;7:525-7.

8 Kathpalia S, Lolans V, Levandowski R, Jackson GG. Resistance to all aminoglycoside antibiotics in enterococcal endocarditis. Clin Res 1984;32:372.

9 Holliman RE, Smyth E. Gentamicin-resistant enterococci and endocarditis. Postgrad Med F 1989;65:390-3.

10 Stevens PJ, Hutchinson NA, Holliman RE. High level gentamicin resistance in enterococcal and streptococcal isolates from blood cultures. Med Lab Sci 1992;49:16-9. 